\title{
Universiteit
}

Leiden

The Netherlands

\section{Trapped at the edge: on long-distance pair-list readings}

Cheng, L.L.; Demirdache, H.

\section{Citation}

Cheng, L. L., \& Demirdache, H. (2010). Trapped at the edge: on long-distance pair-list readings. Lingua, 120(3), 463-484. doi:10.1016/j.lingua.2008.07.008

Version:

Publisher's Version

License: Licensed under Article 25fa Copyright Act/Law (Amendment Taverne)

Downloaded from: $\quad$ https://hdl.handle.net/1887/3245536

Note: To cite this publication please use the final published version (if applicable). 


\title{
Trapped at the edge: On long-distance pair-list readings
}

\author{
Lisa Lai-Shen Cheng ${ }^{\mathrm{a}, *}$, Hamida Demirdache ${ }^{\mathrm{b}}$ \\ ${ }^{a}$ Leiden University, Department of Linguistics, P.O. Box 9515, 2300 RA Leiden, The Netherlands \\ ${ }^{\mathrm{b}}$ Université de Nantes, LLING EA 3827, The Netherlands \\ Received 6 March 2008; received in revised form 8 July 2008; accepted 8 July 2008 \\ Available online 14 May 2009
}

\begin{abstract}
This paper discusses a pair-list reading which we call the trapped pair-list reading, arising in long distance questions with three wH-phrases, two of which are embedded within a subordinate clause. Under the trapped pair-list reading, all three wHS are answered, but only the two wHs trapped inside the embedded clause can be paired. Based on evidence from a language with (overt) multiple wH-movement (Romanian), we argue that (lists of) trapped pair-list readings in English involve covert multiple partial wHmovement. On this proposal, trapped pair-list readings raise, for multiple partial wH-movement, the same canonical scope paradox that single partial wH-movement raises, since on the relevant list reading, all three wHs have semantically wide, matrix scope, though syntactically, the (only) two wHs that can be paired are trapped at the periphery of the subordinate clause. We suggest that this paradox can be resolved by extending Sternefeld (2001) and Lipták and Zimmermann's (2007) Indirect Dependency Approach to single partial-movement to multiple partial-movement. The basic insight driving this proposal is that the subordinate wHs can be paired independently of the matrix wH because the subordinate clause can be interpreted as a multiple question on its own.
\end{abstract}

(C) 2009 Elsevier B.V. All rights reserved.

Keywords: Multiple questions; Pair list/triple list readings; Long-distance questions; Multiple wH-movement; Partial-movement; Indirect dependency; Covert movement; Successive cyclicity; Island effects; Choice functions

This paper discusses a pair-list ${ }^{1}$ reading that has gone unnoticed in the literature. This reading arises in long distance questions with three wH-phrases, two of which are embedded within a subordinate clause, as illustrated with the configuration in (1). On the relevant list reading, all three wH-phrases are answered, but only the two wh-phrases inside the embedded clause $\left(\mathrm{IP}_{2}\right)$ are paired.

(1) $\left[\mathrm{IP}_{1} \mathrm{Wh}_{1} \ldots \cdot\left[\mathrm{IP2} \ldots \mathrm{Wh}_{2} \ldots \mathrm{Wh}_{3}\right]\right]$

\footnotetext{
* Corresponding author.

E-mail address: 1.1.cheng@umail.leidenuniv.nl (L. L.-S. Cheng).

${ }^{1}$ The judgments on LD pair-list readings reported here are based on questionnaires circulated in 2005-2006. We thank Michael Hegarty, Kyle Johnson, Tami Kaplan, David Pesetsky and Chris Tancredi, for their judgments or/and discussion of English, Dafina Ratiu for Romanian, Arthur Stepanov and Sergey Avrutin for Russian, and Boban Arsenijevic for Serbo-Croatian. We are particularly indebted to Chris Tancredi for insightful discussion of the English data, to Dafina Ratiu for bringing to our attention the trapped pair-list reading in Romanian, to Crit Cremers and Orin Percus for long discussions of multiple questions, and to Malte Zimmermann for precious comments and suggestions on how to account for the semantics of the trapped pair list reading. All errors and caveats are our own.
} 
We call this reading the trapped pair-list reading because, although it involves pairing only two out of three wH-expressions, crucially not any two whs can be paired. That is, the configuration in (1) gives rise to pairing asymmetries: the matrix (overtly fronted) wH-phrase (wH1) cannot be paired across the subordinate clause with either wH 2 or wH 3 independently of the third wH. ${ }^{2}$ In other words, only the two wH-phrases inside the embedded clause can be paired. The list of pairs is thus confined to, (i.e., trapped) inside the subordinate clause.

We will further see that the configuration in (1) also allows a list of trapped pair-list readings, where the answer lists different values for the matrix as well as the embedded wHs, while at the same time pairing the embedded wHs, independently of the matrix wH. Once again, however, the same pairing asymmetries arise: only the two wHS within the subordinate clause can be paired independently of the matrix one. In other words, a list reading supplying different values for all three wHs, while at the same time pairing wH1 and either wH2 or wH3 (independently of the third wH) is unavailable.

After discussing mono-clausal pair-list readings (section 1) and long distance pair-list readings (section 2), we present the trapped pair-list reading in section 3 . We then explore the possibility that our trapped pair-list reading is, in fact, a species of (can be derived from) the triple-list reading. Our discussion leads to the following conundrum:

i. On the basis of English, where the syntax of multiple wH-movement is not transparent, and because of a mysterious property of the exhaustivity requirement in LD lists, we could conclude that the answer is yes. That is, the trapped pair-list reading could indeed be derived from the triple-list reading (section 4).

ii. On the basis of Romanian (Ratiu, 2005), where the syntax of multiple wh-movement is overt, we argue that the answer is no. That is, the trapped pair-list reading is not reducible to the triple-list reading as these two readings have a distinct syntax: the former involves multiple partial-movement to the left periphery of the subordinate clause in (1), while the latter involves multiple long-distance movement (section 5).

We conclude that (lists of) trapped pair-list readings in English also involve partial wh-movement, just like in Romanian. The difference between the two languages rests upon the fact that in English, partial wH-movement is covert, while in Romanian, partial wH-movement is overt. We then draw the implications of the generalizations put forth here for the LF-syntax of long-distance list readings (section 5.2). We argue that the comparative distribution of these readings provides evidence for both covert cyclic and non-cyclic (one single step) movement of in-situ wh-phrases - as also argued by Agüero-Bautista (2001) on independent grounds. While non-cyclic (one single step) movement can span an island, cyclic covert movement (just like cyclic overt movement) is subject to strict locality conditions-and, as such, unavailable from the periphery of an island.

The evidence presented here for island effects at LF and, consequently, for covert successive cyclic movement, is important in light of recent proposals according to which successive cyclicity is uniformly reducible to PF Interface conditions on linearization. Our proposal implies that locality effects on movement are not uniformly reducible to PF Interface conditions.

We argue that our trapped pair-list reading raises-for multiple partial wH-movement-the canonical scope paradox that single partial wH-movement raises (section 6.1), since on the relevant list reading, all three wH-phrases are answered (and thus, have semantically wide, matrix scope), though syntactically, the (only) two wh-phrases that can be paired in the answer are trapped at the left-periphery of the subordinate clause in (1).

We suggest that this scope paradox can be resolved by extending Sternefeld (2001, 2002) and Lipták and Zimmermann's (2007) Indirect Dependency Approach to (overt) single partial-movement in embedded argument/ adjunct clauses to covert (in English)/overt (in Romanian) multiple partial-movement in embedded argument/adjunct clauses. The basic insight driving this proposal is that only the subordinate wHs can be paired independently of the matrix wH because the subordinate clause in (1) can be interpreted as a multiple question on its own (section 6.2).

\section{List readings}

As is well known, a multiple question such as (2a) admits both the single-pair and the pair-list readings, illustrated in (2b) and (2c), respectively. ${ }^{3}$

\footnotetext{
${ }^{2}$ This pattern of pairing asymmetries also holds with three wHs within a single clause. Although, we do not discuss monoclausal patterns here, our proposal extends to these configurations. See Cheng and Demirdache (in preparation), as well as Ito (2005) for discussion of monoclausal list readings with three wHs.

${ }^{3}$ (2) also admits an echo interpretation to be distinguished from the single pair reading and which we set aside here.
} 
(2) a. Who bought what?

b. Sybren bought a plane.

c. Sybren bought a plane, Amina bought a train and Zara bought a bicycle.

Under the single pair reading, the identity of a unique pair of individuals is at issue. Dayal (2002) provides the example in (3) to show that single-pair readings are available in English multiple questions, contra Bošković (2001), who argues that languages with overt wH-movement, such as English, do not allow single pair readings with non D-linked wH-words.

(3) Who hit who first?

We adopt the proposal that wH-expressions can quantify over functions from individuals to individuals and that list answers involve functional dependencies (see Engdahl, 1986; Chierchia, 1993; Dayal, 1996a, 2002; Comorovski, 1996 or Hornstein, 1995 among others). Dayal (1996a) gives the following analysis of list readings.

(4) a. Which philosopher likes which linguist?

b. [which linguist $t_{j}$ [which philosopher ${ }_{i}\left[t_{i}\right.$ likes $\left.\left.\left.t_{j}^{i}\right]\right]\right]$

c. $\quad \lambda_{\mathrm{p}} \exists \mathrm{f}_{\langle\mathrm{e}, \mathrm{e}}[\operatorname{Dom}(\mathrm{f})=$ philosopher $\&$ Range $(\mathrm{f})=$ linguist

$\& \mathrm{p}=\cap \lambda \mathrm{p}^{\prime} \exists \mathrm{x}\left[\mathrm{p}^{\prime}=\mathrm{x}\right.$ likes $\left.\left.\mathrm{f}(\mathrm{x})\right]\right]$

d. $\{a$ likes $b$ and $\mathrm{c}$ likes $\mathrm{d}$, a and $\mathrm{c}$ both like $\mathrm{b}$, $\mathrm{a}$ and $\mathrm{c}$ both like $\mathrm{d}$, a likes $d$ and $c$ likes $b\}$

e. $\operatorname{Ans}(\mathrm{Q})=\operatorname{tp}\left[{ }^{\mathrm{v}} \mathrm{p} \& \mathrm{p} \in \mathrm{Q} \& \forall \mathrm{p}^{\prime} \in \mathrm{Q}\left[{ }^{\mathrm{v}} \mathrm{p} \mathrm{p}^{\prime} \rightarrow \mathrm{p} \subseteq \mathrm{p}{ }^{\prime}\right]\right]$

On Dayal's proposal, the in-situ wH-expression in (4a) is interpreted via a skolem function. Which linguist raises at LF, leaving a complex trace consisting of a skolem function variable and an argument variable, represented as the doubly indexed trace in (4b). The subscripted index bound by the wH-phrase is the functional variable and the superscripted index, an individual variable bound by the function's argument (the c-commanding subject argument). (4) thus gives rise to a functional dependency between the subject term, which sets the domain of the function (philosophers), and the object term, which sets its range (linguists). Supposing the set of philosophers is $\{a, c\}$ and the set of linguists is $\{b, d\}$, we get a pair list reading for (4a) because each of the four propositions in the denotation of the question in (4d) is a conjunction of the atomic propositions obtained by varying values of $x$ and its dependent $\mathrm{f}(x)$ in the question nucleus denoted by IP. The functional reading of the question thus denotes a set of propositions relating each individual in the domain set to a functionally dependent entity in the range set. The answerhood operator in (4e) picks out a unique maximally true proposition from the question denotation.

On this proposal, pair-list readings crucially involve LF-movement since the wH-in-situ must scope out of IP in order to create the functional trace, contra recent proposals (e.g. Reinhart, 1998) arguing for an analysis of wh-in situ without LF movement. ${ }^{4}$ However, as Dayal points out, Reinhart's choice function analysis of wH-in situ in (5) cannot generate list answers: the denotation of the question (5a) is a set of atomic propositions (5d), the answerhood operator picks out one of them in a given context. In other words, choice function yields a single-pair answer only.

(5) a. Which philosopher likes which linguist?

b. [which philosopher ${ }_{i}\left[t_{i}\right.$ likes which linguist $\left.]\right]$

c. $\quad \lambda_{\mathrm{p}} \exists \mathrm{x} \exists \mathrm{f}_{\langle\langle(\mathrm{et}) \mathrm{e}}[\mathrm{philosopher}(\mathrm{x}) \& \mathrm{p}=\mathrm{x}$ likes $\mathrm{f}($ linguist $)]$

d. $\{a$ likes b, c likes d, a likes $d, c$ likes b

\footnotetext{
${ }^{4}$ A reviewer asks whether the functional interpretation of wH-questions requires scoping out the (object) wH-phrase in (4a), all the way out of the matrix IP. On Dayal's proposal, the functional reading arises from the denotation for $\mathrm{C}^{\circ}$ (given in (i) below) which introduces three variables, two of which are property variables standing for the domain and the range of the function (i.e., Y and X, respectively, in (i)). Movement to the Spec of (the matrix) $\mathrm{C}^{\circ}$ is required in order to ensure that the wH-expressions end up fixing the values of these variables. Crucially, the first argument to combine with $\mathrm{C}^{\circ}$, thus setting the domain of the function, is the wH-phrase that is structurally closest to $\mathrm{C}^{\circ}$ at $\mathrm{LF}$ - that is, the one that has moved to $\mathrm{Spec} \mathrm{CP}$ in the overt syntax. The second argument to combine with $\mathrm{C}^{\circ}$, thus setting the range of the function, is the higher wH-phrase at LF-that is, the one that has moved to Spec CP in the covert syntax (on the assumption that LF movement extends the tree).
}

(i) $\left[\mathrm{C}^{0}\right]=\lambda \mathrm{Q} \lambda \mathrm{Y} \lambda \mathrm{X} \exists \mathrm{f}\left[\operatorname{dom} \mathrm{f}=\mathrm{Y} \& \forall \mathrm{y}(\mathrm{X}(\mathrm{f}(\mathrm{y}))] \& \mathrm{p}=\cap \lambda \mathrm{p}^{\prime} \exists \mathrm{y}\left[\mathrm{Y}(\mathrm{y}) \& \mathrm{p}^{\prime}={ }^{\wedge} \mathrm{Q}(\mathrm{y})(\mathrm{f})\right]\right.$ 


\section{Long distance list readings}

According to Dayal (2002), long distance list readings across an island are available only if the in-situ wh-phrase is embedded within a wH-island. She gives the following paradigms to illustrate this generalization. (6) allows both a single pair and a list of pairs answer. In contrast, (7) only allows the single-pair reading in (7b), and not the pair-list reading in (7c).

(6) a. Which student knows where Mary bought which book?

b. $\checkmark$ Single pair:

John knows where Mary bought $A$ spects.

c. $\checkmark$ List of pairs:

John knows where Mary bought Aspects and Bill knows where she bought Barriers.

(7) a. Which linguist will be offended if we invite which philosopher?

b. $\checkmark$ Single pair:

Professor Smith will be offended if we invite Professor Brown.

c. \#/*List of pairs:

Professor Smith will be offended if we invite Professor Brown, and Professor King will be offended if we invite Professor Matthews.

On the standard assumption that possible answers specify values for all and only those wH-expressions that have matrix scope, the availability of the list of pairs answer in (6c) signals that the wH-phrase, which book, embedded within the wHisland takes matrix scope, while the unavailability of the list answer in (7c) signals that a wH-phrase embedded within a non wH-island cannot take matrix scope. Dayal resolves this apparent conundrum with the following two assumptions.

First, covert wh-movement across islands is not a legitimate option, as it would violate locality constraints on movement (subjacency). This assumption automatically rules out the list reading in (7c) and, more generally, longdistance list-readings across islands: the functional reading is not available since the in-situ wH cannot scope out of IP to create the required functional trace. (7a) can thus only be interpreted via Reinhart's choice function analysis of wHin situ (as in (5)), yielding the single pair reading in (7b).

Why then are long-distance list readings available across wH-islands? Because the functional reading can arise by relating the matrix subject wH and the wH-complement clause itself. As shown in (8a), the derivation of the list reading does not violate locality constraints on LF-movement since it does not involve scoping out the in-situ wH-phrase, but rather scoping out the wH-complement clause containing the in-situ wH-phrase. The embedded wH-clause is interpreted as a second order question. It denotes the set of questions in (8b). The list reading of (6a) thus involves a functional dependency between the members of this set of questions and individual students who know answers to them.

(8) a. [[where Mary bought which book $]_{i}\left[\right.$ which student $\left[t_{j}^{i}\right.$ knows $\left.\left.\left.t_{i}\right]\right]\right]$

b. $\mathrm{Q}_{\mathrm{i}}=\{$ where Mary bought $A$, where Mary bought $\mathrm{B}$, where Mary bought $\mathrm{C}$ \}

c. $\quad \lambda \mathrm{p} \exists \mathrm{x} \exists \mathrm{f}_{\langle\langle\mathrm{s}, \mathrm{t} t \mathrm{t}\rangle\rangle}\left[\operatorname{Dom}(\mathrm{f})=\mathrm{Q}_{\mathrm{i}} \& \operatorname{Range}(\mathrm{f})=\operatorname{student} \& \mathrm{p}=\cap \lambda \mathrm{p}^{\prime} \exists \mathrm{q} \in \mathrm{Q}_{\mathrm{i}}\left[\mathrm{p}^{\prime}=\operatorname{know}(\mathrm{f}(\mathrm{q})), \mathrm{q}\right]\right]$

We devised a questionnaire in order to test systematically locality conditions on multiple wHs and, in particular, islands restrictions on pair-list readings (see footnote 1). The results of the survey that we carried out to investigate long-distance pair list readings do not, however, validate Dayal's generalization that long-distance lists are confined to wH-islands. The speakers we consulted systematically accepted pair-list readings across islands other than wH-islands. Note, in particular, that in the context provided by Chris Tancredi (p.c.) in (9a), not only is the pair-list reading in (9c) available, it is in fact the only legitimate answer. The single pair reading in (9d) is not appropriate in the given context.

(9) a. Context: each of two philosophers will be offended if we invite one of two linguists.

What I want to know is,

b. Q: Which philosopher will be offended if we invite which linguist?

c. A: Quine will be offended if we invite Chomsky and Lewis will be offended if we invite Kayne.

d. \#A: Quine will be offended if we invite Chomsky

We conclude that long-distance (henceforth LD) list readings are available across islands. 


\section{3. (Lists of) Trapped pair-list readings}

We now discuss an instance of licit pair-list readings, hitherto unnoticed in the literature to our knowledge-except for Ratiu (2005) who identifies this reading in Romanian (section 5).

In our survey of LD list-readings, long-distance questions with either two or three whs were submitted with no context provided. For multiple questions with three whs, informants were asked if they accepted list of triples answers and, further, if they could answer all three whs, while pairing only two out of three whs. Speakers were asked to specify which pairings they allowed (which two whs could be paired independently of the third one) and to explicitly provide possible and impossible answers (and contexts if appropriate).

Thus, consider the multiple LD question in (10a) with two wH-phrases in situ within a purpose clause. (10a) was judged by our informants to allow, a LD single triple answer (e.g., only one triple parent-child-toy), as well as a LD list of triples answer (e.g., multiple parent-child-toy triples):

(10) a. Which parent thanked Mary for giving which child which toy?

b. $\checkmark$ Single triple:

John thanked Mary for giving Sybren a plane.

c. $\checkmark$ List of triples:

John thanked Mary for giving Sybren a plane, and Terry thanked Mary for giving Zara a ball.

Following Dayal (2002), we assume the LD single triple reading in (10b) is derived via a choice function analysis of the in-situ wH-expressions à la Reinhart ((5)). As we shall see in the next sections, the LD list of triples reading in (10c) can be subsumed under a functional reading, derived via long distance LF movement of the in-situ phrases. $^{5}$

Now, (11a) was judged by all our informants to also allow the pair list answer illustrated in (11b) which only pairs the two wHs within the island, but not to allow the list answers in (11c-d), which pairs two (out of three) wHs across the island.

(11) a. Which parent thanked Mary for giving which child which toy?

Pairing the 2 WHs within the island:

b. $\checkmark$ John thanked Mary for giving Sybren a car, Amina a plane, and Zara a ball.

Pairing $2 \mathrm{WH}$ s across the island:

c. \#John thanked Mary for giving Sybren a plane, Terry thanked her for giving Amina a plane, and Chris thanked her also for giving Zara a plane

d. \#John thanked Mary for giving Sybren a plane, Terry thanked her for giving Sybren a train, and Chris thanked her for giving Sybren a car.

Note, crucially, that, on the volunteered list reading in (11b), all three wHS are answered, the list of pairs, however, is confined to the island. That is, the answer in (11b) supplies a single value for the highest wH (wH1), base-generated outside the island, while pairing different values for the two wHs (wH2, wH3) within the island. This is the trapped pair-list reading. Now, although (11a) allows an answer where only two out of the three wH-expressions can be paired, it gives rise to pairing asymmetries: not any two whs can be paired. The judgments were consistent. The matrix (overtly fronted) wh-phrase (wH1) cannot be paired across the island with either $\mathrm{wH}_{2}$ or $\mathrm{wH}_{3}$-independently of the third wH. The list reading is thus trapped within the island.

Questions come with a presupposition that should be satisfied by the context in which the question is asked as well as by the answer to the question. However, even if we supply the context (the presuppositions) satisfying the question and the targeted answer in order to facilitate the (unavailable) list readings in (11c-d), these list answers remain infelicitous. The question-answer pair in (12) thus contrasts sharply with the infelicitous question-answer pairs in (13)-(14).

\footnotetext{
${ }^{5}$ We argue in section 5.2 that that LF movement of wH-in-situ in (10a) is non-cyclic (one single step) movement and, as such, can (contra Dayal) span an island.
} 
Context for pairing the WHs within the island: WH2-WH3

I know one of these parents thanked Mary for giving different children different toys.

What I want to know is:

a. Which parent thanked Mary for giving which child which toy?

b. $\checkmark$ John thanked Mary for giving Sybren a car, Amina a train, and Ilea a plane.

Context to facilitate pairing of $2 \mathrm{WH}$ s across an island: $\mathrm{WH} 1-\mathrm{WH} 2$

Different parents thanked Mary for giving different children the same toy.

a. Which parent thanked Mary for giving which child which toy?

b. \#John thanked Mary for giving Sybren a plane, Terry thanked her for giving Amina a plane, and Chris thanked her also for giving Zara a plane

Context to facilitate pairing of 2 WHs across an island: WH1 - WH3

Different parents thanked Mary for giving one of these children different toys.

a. Which parent thanked Mary for giving which child which toy?

b. \#John thanked Mary for giving Sybren a plane, Terry thanked her for giving him a train, and Chris thanked her for giving him a car.

The same pairing asymmetries arise in other types of islands with three wH-phrases: a complex NP island in (15) and an adjunct island in (16). In each case, all three whs can be answered but only the two whs inside the island can be paired independently of the matrix wH. That is, only the two wHs trapped within the island can always be paired in the answer.

(15) a. Which boy spread the rumor that which guest had brought which toy?

b. $\checkmark$ (which guest, which toy)

Billy spread the rumor that Mrs. Johnson brought the plane, Mr. McGregor, the train, and Ms. Brown, the car.

c. *(which boy, which toy)

\#Billy spread the rumor that Mrs. Johnson brought the plane, Johnny spread the rumor that Mr. Johnson brought the train, and Eddy spread the rumor that Mr. Johnson brought the car.

d. *(which boy, which guest)

\#Billy spread the rumor that Mrs. Johnson brought the plane, Johnny spread the rumor that Mr. McGregor brought the plane, and Eddy spread the rumor that Mr. Johnson brought the plane.

(16) a. Which teacher got upset because which boy had a fight with which girl?

b. $\checkmark$ (which boy, which girl)

The history teacher got upset because John had a fight with Mary, and Bill a fight with Susan.

c. *(which teacher, which girl)

\#The history teacher got upset because John had a fight with Mary, and the math teacher got upset because John had a fight with Susan.

d. *(which teacher, which boy)

\#The history teacher got upset because John had a fight with Mary and the math teacher got upset because Bill had a fight with Mary.

Note, moreover, that the trapped pair-list reading is not restricted to islands, as illustrated in (17a-c). But again, only the two wHS within the embedded clause can be paired independently of the third (matrix) wH.

(17) a. Which guest promised to give which child which toy?

$\checkmark$ Bill promised to give Sybren the plane and Amina the train.

b. Which guest promised that he would give which toy to which child?

$\checkmark$ Bill promised that he would give the plane to Sybren and the train to Amina.

c. Which guest promised that which child would get which gift?

$\checkmark$ Bill promised that Sybren would get the plane, and Amina the train. 
Now, importantly, a list of trapped pair-list readings is also available, as illustrated below. The answers in (18b) and (19b) thus list different values for the matrix as well as the embedded whs, while at the same time pairing the embedded wHs, independently of the matrix wH.

(18) a. Which guest promised that which child would get which toy?

b. John promised that Sybren would get a plane and Amina a train, and Terry promised that Zara would get a ball and Ilea a teddy bear.

(19) a. Which parent thanked Mary for giving which child which toy?

b. John thanked Mary for giving Sybren a plane and Amina a train, and Terry thanked Mary for giving Zara a ball and Ilea a teddy bear.

Once again, however, the same pairing asymmetries arise: only the two whs within the island can be paired independently of the matrix one. Thus, a list reading supplying different values for all three whs, while at the same time pairing wH1 and either wH2 or wH3 (independently of wH1), is infelicitous as an answer to (19):

(20) a. *John thanked Mary for giving Sybren a plane, Terry thanked Mary for giving Sybren a train, Chris thanked Mary for giving Zara a ball, and Billy thanked Mary for giving Zara a teddy bear.

b. *John thanked Mary for giving Sybren a plane, Terry thanked Mary for giving Zara a plane, Chris thanked Mary for giving Amina a train, and Billy thanked Mary for giving Ilea a train.

\section{Can the (list of) trapped pair-list reading be generated as a subset of the triple-list reading?}

We now turn to the issue of how to generate the trapped pair-list reading, while accounting for the pairing asymmetries discussed above. We first consider whether Dayal's account of list readings with multiple whs can generate the trapped list reading. In particular, can trapped pair-list answers be generated as a subset of triple list answers? To answer this question, we first run through two core properties of list answers, as reported in the literature. ${ }^{6}$

\subsection{Properties of pair-list readings}

According to many authors, pair-list answers must be exhaustive (see É. Kiss, 1993; Comorovski, 1996, or Dayal, 1996a). To illustrate, consider (21) in a context where single tennis games between men and women are being organized. The argument goes as follows. In a context where there are more women players than men players, (21a) is judged felicitous. The fact that one woman is not paired, as represented in $(21 \mathrm{~b}){ }^{7}$ does not appear to matter. In contrast, (21a) would be infelicitous in a context where there are more men than women.

(21) a. Which man is playing against which woman?

b. $\quad$ Men $\rightarrow$ Women

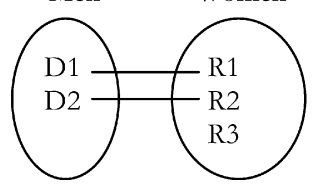

The conclusion is that the list answer to (21a) must exhaustively pair every member of the subject term but not necessarily every member of the object term. Recall that for Dayal (1996a) the overtly fronted wH (that is, the subject

\footnotetext{
${ }^{6}$ The reader should keep in mind that, although we take for granted, in this section, for the sake of the argument, Dayals' assumptions that only the domain (as opposed to the range) of the function involved in list readings must be exhausted, and that non-bijective many to one (as opposed to one to many) pairings are allowed, we leave these issues, in fact, open in this paper. If these assumptions turn out not to be justified or to be too strong, then the account we suggest here of pairing asymmetries in LD lists with three wHs, on Dayal's analysis of LD-list readings, would not go through in the first place.

${ }^{7}$ In the set-diagrams that follow, D stands for the domain of the function involved in a list answer, and R for its range.
} 
wH-phrase in (21a)) sets the domain of the function, while the in-situ wH sets its range. In other words, the wH that must be exhausted is the one that sets the domain of the function. (While on both É. Kiss' (1993) and Comorovski's (1996) analyses, the wH that is exhausted is the wH-operator with the widest scope.)

The second property of list answers concerns the nature of the pairings. The question is whether or not the pairings involved must be bijective. Dayal argues that although there is a strong tendency for the pairings to be bijective, they need not be, and gives the following contrast in support of this generalization (see also Engdahl, 1986 for discussion).
a. Which student read which book?
b. John read Moby Dick and Bill read Moby Dick too.
c. \# John read Moby Dick and War and Peace.

Speakers admit (22b) as an answer to (22a), but in order to admit (22c) as an answer, which book has to be changed to which books. Dayal concludes that multiple wh-questions do not enforce one to one pairings: they allow many to one pairings as illustrated in (23), but not one to many pairings.

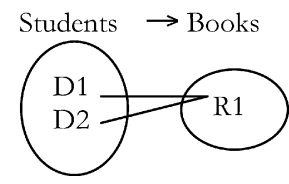

\subsection{Multiple questions with three wHS}

We now turn to the question of how to analyze multiple questions with three whs, such as (24). We consider two options suggested in the literature (see Dayal, 1996a; Hornstein, 1995 or Lewis, 1999) to generate the list of triples reading via functional dependencies.

On the first option given in (24i), the in-situ wH-phrases each introduce a skolem function (ranging over children and toys, respectively) whose argument variable is bound by the subject wH. The subject term thus sets the domain (parents) for both functions. The interpretation of (24) thus involves two functions, one from parents to children and the other from parents to toys. ${ }^{8}$ On the second option given in (24ii), we would again have two functions, but this time one from parents to children and the other from children to toys, and these two functions undergo function composition.

(24) Which parent gave which child which toy?

i. Two functions, one from parents to children \& one from parents to toys: [which child ${ }_{i}$ [which toy, [which parent ${ }_{k}\left[t_{k}\right.$ gave $\left.\left.t_{i}^{\mathbf{k}} t_{j}^{\mathbf{k}}\right] 1\right]$

ii. Two functions, one from parents to children \& one from children to toys: [which child ${ }_{i}\left[\right.$ which toy $\left[\right.$ which parent $t_{k}\left[t_{k}\right.$ gave $\left.\left.t_{i}^{k} t_{j}^{i}\right]\right]$

\subsection{Back to the trapped pair-list reading}

With this background in mind, let's go back to the issue of whether trapped pair-list answers can be generated as a subset of triple-list answers. Suppose the set of parents in the situation is $\{\mathrm{P} 1, \mathrm{P} 2\}$, the set of kids is $\{\mathrm{C} 1, \mathrm{C} 2\}$ and the set of toys is $\{\mathrm{T} 1, \mathrm{~T} 2\}$. On the triple list reading, the question in (25a) will have the denotation in (25b) (assuming for simplicity a situation where each parent thanks Mary for a single and different child-toy pair). The triple-list reading arises because each proposition in the set in (25b) is a conjunction of atomic propositions and the Q operator picks out a unique maximally true proposition in this set.

\footnotetext{
${ }^{8}$ Dayal (1996:118, fn 29) gives the translation in (i) for the representation in (24i).

(i) $\lambda \mathrm{p} \exists \mathrm{f}_{1} \exists \mathrm{f}_{2}\left[\forall \mathrm{x}\right.$ child' $\left(\mathrm{f}_{1}(\mathrm{x})\right) \wedge \forall \mathrm{x}$ toy' $\left(\mathrm{f}_{2}(\mathrm{x})\right) \wedge \mathrm{p}=\cap \lambda \mathrm{p}^{\prime} \exists \mathrm{y}\left[\right.$ parent' $(\mathrm{y}) \wedge \mathrm{p}^{\prime}=\wedge$ give' $\left.\left.\left(\mathrm{y}, \mathrm{f}_{2}(\mathrm{y}), \mathrm{f}_{1}(\mathrm{y})\right)\right]\right]$
} 
Now, if the set of possible answers to (25a) is merely the list of all possible parent-children-toy triples (25b), then we cannot generate trapped pair-list answers as a subset of triple-list answers. That is, the denotation of the question in (25a) on the trapped pair list reading would be the set of four propositions in (26), and this set is not a subset of the set given in (25b).

(25) a. Which parent thanked Mary for giving which child which toy?

b. Q denotation under the triple list reading:

$\{\mathbf{P 1}$ thanked Mary for giving C1 T1 and P2 thanked Mary for giving C2 T2,

$\mathbf{P} 2$ thanked Mary for giving C1 T1 and P1 thanked Mary for giving C2 T2,

P1 thanked Mary for giving C1 T2 and P2 thanked Mary for giving C2 T1,

P2 thanked Mary for giving C1 T2 and P1 thanked Mary for giving C2 T1

\section{$Q$ denotation under the trapped pair-list reading \\ $\{\mathbf{P} 1$ thanked Mary for giving C1 T1 and P1 thanked Mary for giving C2 T2, \\ P2 thanked Mary for giving C1 T1 and P2 thanked Mary for giving C2 T2, \\ P1 thanked Mary for giving C1 T2 and P1 thanked Mary for giving C2 T1 \\ P2 thanked Mary for giving C1 T2 and P2 thanked Mary for giving C2 T1}

We have seen, however, in the preceding section, that list answers need not involve bijective, one-to-one mapping between the sets defining the range and the domain of the function, and, moreover, need not exhaust the set defining the range of the function. Given these assumptions, then the set of possible answers to (25a) will include list answers pairing only two whs out of three. The question, however, is whether these assumptions guarantee that we generate only the set of empirically attested trapped pair list readings in (26) from the set of theoretically possible triple-list answers. In other words, do these assumptions suffice to ensure that we do not also generate empirically non-attested pair list readings (i.e., unattested list answers pairings either only parents and children, or only parents and toys as in $(11 \mathrm{c}-\mathrm{d}))$. Lets see if this is the case or not.

Recall that in cases with two whs (21), the subject term (that is, the overtly fronted wH which man) sets the domain of the function. The null assumption is then that, in cases with three whs such as (25a), the subject term (that is, the overtly fronted wH which parent) is likewise also the domain setter. But then the pairings in (26) violate both exhaustivity (since no answer pairs both members of the domain: P1 and P2) and the ban on one-to-many pairings (since either P1 or P2 is always mapped onto two child-toy pairs in each of the four possible answers). But this is the case, only under the assumption that the overtly fronted wH (that is, the matrix subject which parent) sets the domain for either both of the functions (option (24i) above) or for the composite function (option (24ii)), involved in the interpretation of multiple questions with three whs. That is, if we assume that wH1 (the matrix subject) does not set the domain of the function(s), then neither exhaustivity, nor the ban on one-to-many parings will be violated, and trapped pair-list answers could then perhaps be generated as a subset of triple list answers. We consider this possibility directly below.

First consider option (24i) for interpreting questions with three wHs. Then either wH 2 or wH 3 sets the domain of both functions. For concreteness, assume the dative term is the domain setter. We thus have two functions, one from children to toys and one from children to parents:

(27) a. Which parent thanked Mary for giving which child which toy?

b. $\quad\left[\right.$ which child $_{\mathbf{i}}\left[\right.$ which toy ${ }_{j}\left[\right.$ which parent $\mathbf{k}_{\mathbf{k}}\left[\mathrm{t}_{\mathbf{k}}^{\mathrm{i}}\right.$ thanked Mary for giving $\left.\left.\mathrm{t}_{\mathbf{i}} \mathrm{t}_{\mathbf{j}}^{\mathrm{i}}\right]\right]$

On this analysis, the trapped pair-list reading would involve the pairings represented in (28).

Trapped pair-list reading (pairing only Wh2 \& Wh3):

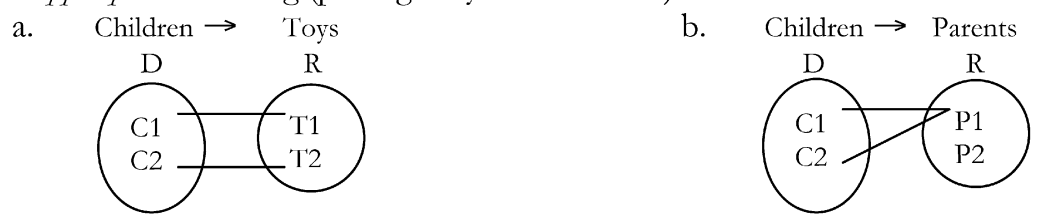


The exhaustivity requirement is satisfied since each individual in the domain setter for both functions (children) is paired with some member in the range of the relevant function. The non-bijective pairings in (28b) are, moreover, legitimate since they involve many-to-one (as opposed to one-to-many) mappings.

But this still does not work. Since once we generate trapped pair-list answers via the non-bijective (many-to-one) pairings in (28b), then we also generate illicit pairings. That is, we also allow the pairings in (29). Note that these pairings satisfy the exhaustivity requirement on the domain of the function. Moreover, the non-bijective pairings in (29a) are acceptable since they involve many-to-one mappings. But the pairings in (29) yields the illicit answer, as in (30b), which pairs wH1 and wH2 across the adjunct island, independently of wH3:

Illicit reading (pairing only WH1 \& WH2)
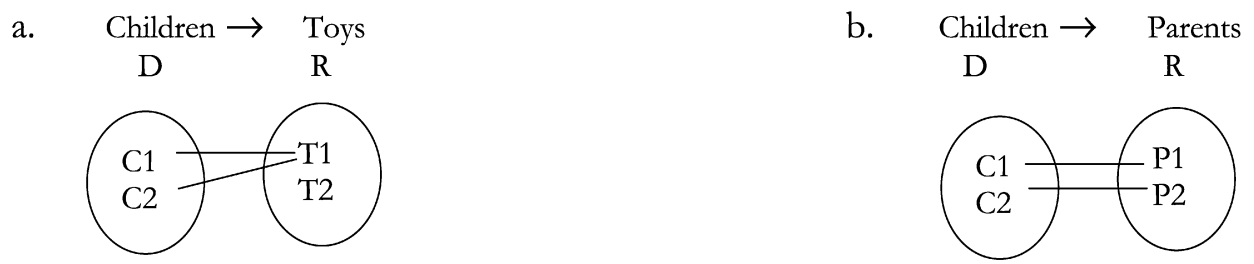

(30) a. Which parent thanked Mary for giving which child which toy?

b. \#John thanked Mary for giving Sybren a plane, and Chris thanked her for giving Amina a plane.

In sum, regardless of whether we assume that it is wH2 or wH3 that sets the domain of both functions, if we assume the analysis in (24i) for lists with three whs, we generate non-attested pair-list readings. That is, we cannot account for the pairing asymmetries in list answers with three whs. We cannot derive the generalization that not any pairing of two wHs is allowed. The matrix wH and the embedded object or dative cannot be paired independently of the third wH.

Lets now consider option (24ii) for interpreting trapped list questions with three wHs. Again it must be the case that wH1 does not set the domain of either of the two functions that undergo function composition, since this would yield a violation of both the exhaustivity requirement and the ban on one-to-many pairings, as we have already seen. For concreteness, assume the dative term is the domain setter. We thus have two functions, one from children to toys and the other from toys to parents:

(31) a. Which parent thanked Mary for giving which child which toy?

b. [which child $d_{i}\left[\right.$ which toy $y_{j}\left[\right.$ which parent $t_{k}\left[t_{k}^{j}\right.$ thanked Mary for giving $\left.\left.t_{i} t_{j}^{i}\right]\right]$

On this analysis, the trapped pair-list reading would involve the pairings represented in (32).

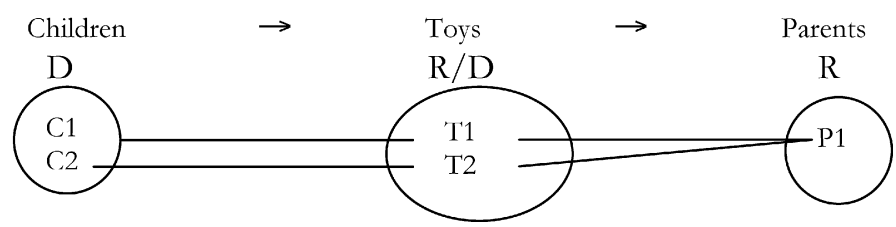

The above pairings satisfy the exhaustivity requirement on the domain setter. Both the dative term (which sets the domain of the function from children to toys) and the object term (which sets the domain of the function from toy to parents) are exhausted. And the non-bijective pairings between toys and parents are legitimate since they involve many-to-one mappings. More importantly, we correctly predict the pairing asymmetries in list answers with three wHs: only the set of parents need not be exhausted since the matrix wH-term (which parent) sets the range of the composite function involved in the interpretation of the question in (31).

Now, in order to make the analysis just sketched work, we had to stipulate that the range of this composite function is the wH overtly fronted to Spec CP (wH1), while the two in-situ whs respectively set the domain of the two functions undergoing function composition in (31b). According to the literature, this ad-hoc stipulation 
appears, however, to be justified. That is, it appears to be a mysterious property of long-distance lists (involving two WHs) that the overt scopal relations of the terms setting the domain and the range of the function get reversed (see Dayal, 1996a:133, Bittner, 1998:57 or Hagstrom, 1998:167). ${ }^{9}$ The generalization in the literature is stated below. ${ }^{10}$

(33) a. Monoclausal multiple questions

Which student will play against which professor?

$\Rightarrow$ Overtly fronted WH determines the domain-set (must be exhausted).

WH in-situ determines the range-set.

b. Biclausal multiple questions

Which linguist knows where Mary bought which book?

$\Rightarrow$ WH in-situ determines the domain-set (must be exhausted).

Overtly fronted WH determines the range-set.

On the above analysis of lists in questions with three wHs, the question in (34a) will now have the denotation in (34b). Note that the last four propositions in (34b) correspond to trapped pair-list answers (see (26)). In other words, we conclude that trapped pair list answers can be generated as a subset of triple list answers.

(34) a. Which parent thanked Mary for giving which child which toy?

b. $Q$ denotation under the triple list reading:

\{P1 thanked Mary for giving C1 T1 and P2 thanked Mary for giving C2 T2,

P2 thanked Mary for giving C1 T1 and P1 thanked Mary for giving C2 T2,

P1 thanked Mary for giving C1 T2 and P2 thanked Mary for giving C2 T1,

P2 thanked Mary for giving C1 T2 and P1 thanked Mary for giving C2 T1

P1 thanked Mary for giving C1 T1 and P1 thanked Mary for giving C2 T2,

P2 thanked Mary for giving C1 T1 and P2 thanked Mary for giving C2 T2,

P1 thanked Mary for giving C1 T2 and P1 thanked Mary for giving C2 T1

P2 thanked Mary for giving C2 T1 and P2 thanked Mary for giving C1 T2

In sum, if we assume (i) that questions with three whs involve function composition, (ii) that the range (as opposed to the domain) of the function need not be exhausted, (iii) that non-bijective many-to-one (as opposed to one-to-many) pairings are allowed, and (iv) the mysterious generalization in (33) according to which the overtly fronted wH in LD lists is not the domain setter, but rather the range setter of the (composite) function, we appear to predict the existence of the trapped list reading since, crucially, we account for the pairing asymmetries in lists with three wHS (as established in section 3): the overtly fronted wH will set the range of the composite function deriving the triple list reading and, hence, is the only term that need not be exhausted.

We will nonetheless argue, in what follows, that the trapped pair-list reading cannot be derived from the triple list reading. The argument we put forth rests upon the overt syntax of multiple wH-movement in Romanian. We will argue that if the trapped pair-list reading could be derived from the triple-list reading, then we expect these two readings to be equally available in the same syntactic environments-but this is not the case in Romanian. Each reading has its own syntax.

\footnotetext{
${ }^{9}$ To quote Hagstrom (1998:167): "In responding to the question Who knows where we bought what?, an answer must be given for each thing bought, but not necessarily for each person who knows about some buying event." In other words, in this LD case with two whs interacting, it is the wH in-situ that must be exhausted (since no item bought can be left unpaired), rather than the overtly fronted (subject) wH (since individuals can be left unpaired). In contrast, recall that in the monoclausal cases involving two wHs (21), it is the subject WH-term that must be exhausted. See Dayal (1996a) and Bittner (1998) for exactly the same claim.

${ }^{10}$ Recall from footnote 2 that monoclausal questions with three wHs also allow pairing two out of three whs, with the same pairing asymmetries (only the overtly fronted wH can be left unpaired). If this is the case, then scope reversal of the terms setting the domain and the range of the function could not be merely a property of LD lists, it would have to extend to all configurations (mono or bi-clausal) involving three wHs undergoing function-composition.
} 


\section{The overt syntax of the trapped list reading: Romanian multiple questions - Ratiu $(2005,2007)$}

We first run through the relevant properties of wH-questions in Romanian. Romanian is a multiple wh-movement language, where wH-phrases are obligatorily overtly fronted to Spec CP, as the ungrammaticality of (35b-c) illustrates.

(35) a. Cine ce vrea?
who what wants
'Who wants what?'
b. *Cine vrea ce?
'Who wants what?'
c. $*$ Ce vrea cine ?
'What does who want?'

WH-extraction across an island is not allowed (36), and leaving a WH-phrase in situ within the island is not allowed either (37).

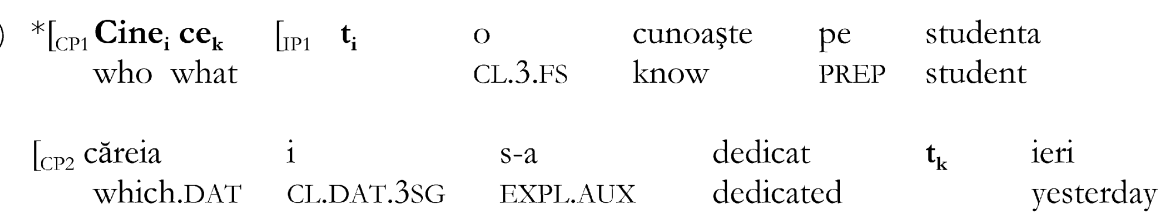

'Who knows the student to whom was dedicated what yesterday?'

(37)

\begin{tabular}{|c|c|c|c|c|}
\hline 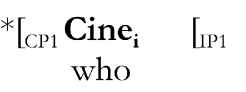 & $\begin{array}{l}\text { o } \\
\text { CL.3.FS }\end{array}$ & $\begin{array}{l}\text { cunoaşte } \\
\text { know }\end{array}$ & $\begin{array}{l}\text { pe } \\
\text { PREP }\end{array}$ & $\begin{array}{l}\text { studenta } \\
\text { student }\end{array}$ \\
\hline $\begin{array}{l}\text { [CP2 căreia } \\
\text { which.DAT }\end{array}$ & $\begin{array}{l}\text { i } \\
\text { CL.DAT.3SG }\end{array}$ & $\begin{array}{l}\text { s-a } \\
\text { EXPL.AUX }\end{array}$ & & $\begin{array}{ll}\mathbf{c e}_{\mathbf{k}} & \text { ieri } \\
\text { what } & \text { yesterday }\end{array}$ \\
\hline
\end{tabular}

'Who knows the student to whom was dedicated what yesterday?'

The questions in (36)/(37) can be rescued by partial wH-movement to the left periphery of the island, as in (38). Note that (38) allows the single pair answer in (39a), but not the pair-list answer in (39b).

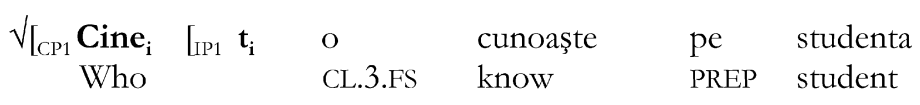

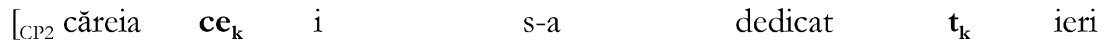

which.DAT what CL.DAT.3SG EXPL.AuX dedicated yesterday

'Who knows the student to whom was dedicated what yesterday?'

(39)
a. VSingle pair:
Vlad knows the student to whom a poem was dedicated yesterday.
b. * List of pairs:
Vlad knows the student to whom a poem was dedicated yesterday,
Filip knows the student to whom a song was dedicated yesterday.

In (40), we see that multiple partial wh-movement to the left periphery of the island is allowed. (40) allows the single triple answer in (41a), but not the list of triples answer in (41b).

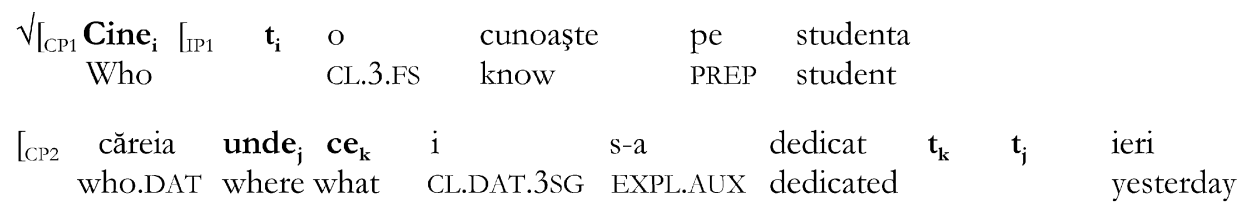

Who knows the student to whom was dedicated what where yesterday? 
(41) a. V Single triple:

Vlad knows the student to whom a poem was dedicated yesterday at the radio station.

b. * List of triples:

Vlad knows the student to whom a poem was dedicated yesterday at the radio station, Filip knows the student to whom a song was dedicated yesterday at a concert

Crucially, however, (40) allows the answer in (41c):

(41) c. VVlad knows the student to whom a poem was dedicated yesterday at the radio station and the student to whom a song was dedicated yesterday at a concert.

This reading is the trapped list reading that we also found in English, where all three whs are answered, and where the two whs trapped within the island can be paired independently of the matrix wH.

(42) instantiates multiple partial wH-movement to the left periphery of a complex NP island. As was the case with (40), this question allows the single triple answer in (43a), the trapped pair-list answer in (43b), but not the list of triples answer in (43c). Note also that the trapped pair-list answer in (43b) is in fact preferred over the single triple answer (43a).

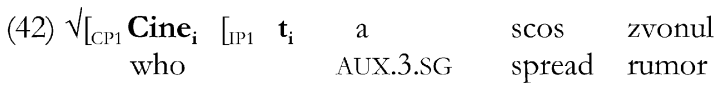

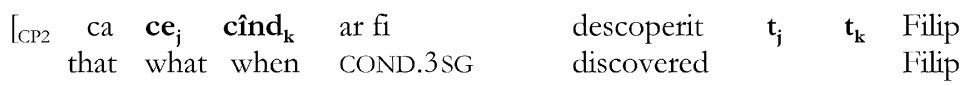

Who spread the rumour that Filip discovered what, when?

(43) a. V Single triple:

Vlad spread the rumour that Filip had discovered the secret of the philosophical stone when he was a child.

b. VTrapped pair-list

Vlad spread the rumour that Filip had discovered the secret of the philosophical stone

when he was a child, an underground city two months ago, and a treasure last week.

c. *List of triples

Vlad spread the rumour that Filip had discovered the secret of the philosophical

stone when he was a child, Claudia spread the rumour that Filip had discovered an underground city two months ago and $A d i$ spread the rumour that Filip had discovered a treasure last week.

(44) illustrates single partial wH-movement to the left periphery of a complement clause, and (45) multiple partial wH-movement. Note that (44) allows both a single pair and a list of pairs answer, while (45), which does not involve an island, allows a single triple, a list of triples and a trapped pair-list answer.

(44)

$$
\begin{aligned}
& \sqrt{ }_{{ }_{\mathrm{CP} 1}} \text { Cine a spus ca ce va offeri satului } \\
& \text { who said that what will offer the village }
\end{aligned}
$$

'Who said that he will offer the village what?

$\sqrt{\text { Single pair }}$

$\sqrt{\text { List of pairs }}$

(45)

$\begin{array}{ccccccc}\sqrt{[C P 1} \text { Cine } & \text { a spus } & \text { ca } & \text { ce } & \text { cind va offeri satului } \\ \text { who } & \text { said } & \text { that } & \text { what } & \text { when will } & \text { offer the village }\end{array}$

Who said that he will offer the village what, when?

$\sqrt{\text { Single triple }}$

$\sqrt{\text { List of triples }}$

$\sqrt{T r a p p e d}$ pair-list answer 
Finally, in (46) and (47), we see that single and multiple long-distance wH-extraction across a complement clause are (respectively) allowed. Crucially, (46) enforces a list of pairs answer, while (47) enforces a list of triples answer. ${ }^{11}$

(46)

$\begin{array}{clllll}\sqrt{ }\left[_{\mathrm{CP} 1} \text { Cine }\right. & \text { ce } & \text { a spus } & \text { ca } & \text { va } & \text { offeri satului } \\ \text { who what } & \text { said that } & \text { will offer the village }\end{array}$

Who said that he will offer the village what?

$\sqrt{\text { Single pair }}$

$\sqrt{\text { List of pairs }}$

(47)

$\begin{array}{rllllll}\sqrt{\Gamma_{\text {СР } 1}} \text { Cine } & \text { cind } & \text { ce } & \text { a spus ca } & \text { va } & \text { offeri satului } \\ \text { who } & \text { when what said that will offer the village }\end{array}$

Who said that he will offer the village what, when?

$\sqrt{\text { Single triple }}$

$\sqrt{\text { List }}$ of triples

$\sqrt{T r a p p e d}$ pair-list answer

In sum, multiple wH-questions involving movement across a complement clause differ from multiple wH-questions involving an island in two respects. First, they allow (overt) multiple LD extraction to the matrix Spec CP (compare (46)/(47) with (36)). Second, partial movement to the periphery of a complement clause also allows a list of pairs/ triples reading (compare $(44) /(45)$ with $(38) /(40) /(42))$.

\subsection{Trapped pair-list readings are not reducible to triple-list readings}

Lets now summarize the relevant generalizations. Configurations with islands such as in (40) or (42), as schematized in (48), allow trapped pair list readings, but do not allow a list of triples readings:

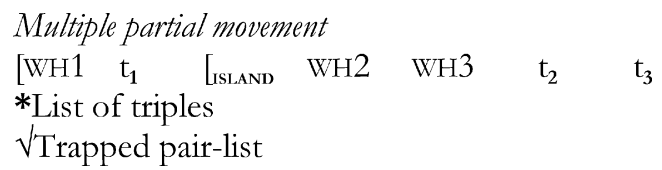

Conversely, configurations without islands such as in (47), as schematized in (49), allow a list of triples readings but do not allow trapped pair-list readings:

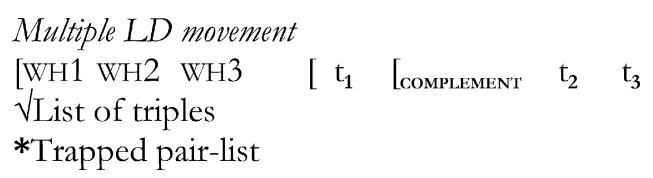

Section 4 had led us to conclude that we could derive the trapped list reading from the list reading, once we assume that (i) questions with three wHs involve function composition, (ii) that the range (as opposed to the domain) of the function need not be exhausted, (iii) non-bijective many-to-one pairings are allowed, and (iv) overt scopal relations of the terms setting the domain and the range of the function get reversed in biclausal questions (see (33)).

Now, if the set of propositions that are possible answers on the trapped list reading are generated as a subset of the set of propositions that are possible answers on the list of triples reading (as in (34) above), then we expect these two readings to be equally available in the same syntactic environments. That is, we expect that (48) should allow a list of triple reading and, conversely, that (49) should allow a trapped pair-list reading. Since, however, the trapped pair-list reading is unavailable in (49) and, conversely, the triple-list reading is unavailable in (48), we conclude that the trapped-list reading cannot be reduced to the triple-list reading (that is, that trapped-list answers cannot be generated as a subset of triple-list answers).

The overt syntax of multiple wH-movement in Romanian thus leads us to conclude that the trapped pair-list reading cannot be derived from the triple-list reading. These two readings have a distinct syntax. The trapped pair-list reading involves multiple partial movement, while the triple-list reading involves multiple long-distance movement.

\footnotetext{
${ }^{11}$ The generalisation that multiple fronting to the matrix spec $\mathrm{CP}$ enforces the list reading (single pair/single triple answers being no longer available) is discussed by Ratiu (2007) for Romanian, Grebenyova (2004a) for Bulgarian, and Bošković (2001).
} 


\subsection{Evidence for island effects with cyclic covert movement}

We now draw the implications of the Romanian data discussed in this section-in comparison to English-for the LF syntax of long-distance list readings. We set aside here the trapped list reading to which return in section 6.

We start by recapitulating the generalizations that have emerged so far. Consider first English. wH-phases in situ within an island allow LD list readings (50). Assuming that list readings involve LF movement (since wH-in-situ must scope out of IP in order to create a functional trace (see discussion of (4), section 1)), ${ }^{12}$ we conclude that there are no island effects for $\mathbf{L F}$ movement of (be it single or multiple) wH-in-situ.

(50) English

LD multiple questions across an island

Overt syntax: WH-in-situ within the island.

$\rightarrow$ Allow LD list answers and trapped pair list answers, ((9)/(10)-(11)).

Turning now to Romanian, the generalizations are summarized in (51).

(51) Romanian

a. LD multiple questions across an island

i. Overt syntax: (single/multiple) movement to the left edge of the IP within the island.

$\rightarrow$ Do not allow LD pair/triple list answers involving the matrix and embedded WH(s), ((38)/(40)-(42)).

b. LD multiple questions: $n$ o island

Overt syntax: partial (single/multiple) movement to the left edge of the embedded IP.

ii. $\rightarrow$ Allow LD pair/triple list answers involving the matrix and embedded wH(s), ((44)-(45)).

Overt syntax: LD multiple movement to the left edge of the matrix CP.

iii. $\rightarrow$ Allow LD pair/triple list answers involving the matrix and embedded wH(s), ((46)-(47)).

Assuming that LD list readings involve LD multiple wH-movement to the matrix CP, we take the unavailability of LD list readings with wHs partially fronted in the syntax to the periphery of an island ((51i)), - and conversely, their availability with wHs partially fronted in the syntax to the periphery of a complement clause ((51ii)) - to mean that covert movement to the matrix CP of partially fronted wHs must be unavailable from the periphery of an island. That is, partially moved wHS are sensitive to island constraints at LF: pairing the partially moved $\mathrm{wH}(\mathrm{s})$ with the matrix $\mathrm{wH}$ (to yield a list answer) is unavailable in (52b), because further covert movement of the partially fronted wH(s) to the matrix spec CP would violate island constraints, but available in (52a) because, in this case, further covert movement will not violate island constraints.
a. Wh1 t $\mathrm{t}_{1} \quad$ CrP $_{\mathrm{CP}}\left[_{\mathrm{IP2}} \mathrm{Wh} 2\right.$
$\left.\left.(\mathrm{Wh} 3) t_{2}\left(t_{3}\right)\right]\right]$
$(44) /(45)$
b. Wh1 t t LsLand Lir2 $\mathrm{Wh} 2$
$\left.(W h 3) t_{2}\left(t_{3}\right)\right]$
$(38) /(40)-(42)$

Now, in contrast to partially moved wHs (Romanian) which show island effects, LD wH-in-situ (English) shows no island effects-since it allows LD list readings $((50))$.

To capture the full set of contrasts in (50)-(51), we assume that LD wH-in-situ can involve a single step movement to the matrix Spec CP. Since movement is non-cyclic (proceeds in a single swoop), it will not be subject to locality conditions. We thus capture the insensitivity of (at least English) wH-in-situ to islands (50). The same conclusion is

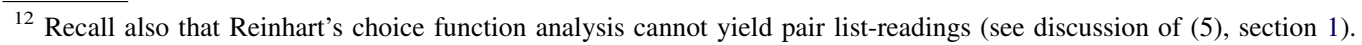


reached by Agüero-Bautista (2001) who argues, on independent grounds, that wH-in-situ involves non-cyclic movement (as opposed to overt wH-movement, which is cyclic movement). ${ }^{13}$

Partial movement, however, is cyclic movement and, as such, is subject to locality effects. This, in turn, captures the contrast between English (wH-in-situ) vs. Romanian (medial-whs), as well as the contrast between island configurations vs. non-island configurations in Romanian.

This proposal is summarized in (53).

(53) a. wH-in-situ can involve a single step movement to the matrix Spec CP. Since movement is non-cyclic (proceeds in a single swoop), it is not subject to locality conditions. ${ }^{14}$

b. Cyclic movement-be it overt or covert—is subject to locality (island) conditions.

Overt—be it partial or LD-movement is cyclic movement. Further covert movement of partially fronted $\mathrm{wH}(\mathrm{s})$ to the matrix $\mathrm{CP}$ is thus subject to locality conditions.

(53a) captures the availability of LD list readings across islands in English. Assuming (53b), both overt single/multiple wH-movement from within a complement clause and covert single/multiple wH-movement from the edge of a complement clause will be legitimate, thus capturing the availability of LD list readings with wHs having undergone, in the syntax, either overt LD (multiple) wH-movement from within a complement clause, or covert (multiple) wH-movement from the left edge of a complement clause, in Romanian (51b).

(53b), however, rules out single/multiple wH-movement from the edge of an island, be it at LF or in the overt syntax, thus accounting for the unavailability of LD list readings with whs having undergone in the overt syntax partial (multiple) wH-movement from within an island, in Romanian $((51 \mathrm{a}) /(52 \mathrm{~b}))$.

If the conclusions we draw from the comparison of the overt syntax of LD readings in English vs. Romanian are correct, then we have evidence for island effects at $L F$ and, consequently, for covert successive cyclic movement. Russian and Serbo-Croatian partial movement provide further evidence for cyclic covert movement. Consider first the English sentence in (54).

(54) Who knows where Mary bought what?

The in-situ wH what can be paired with the matrix wH who. On our analysis, this is possible because the in-situ what has undergone non-successive cyclic covert movement to the matrix Spec CP, and single swoop movement is not subject to locality (island) conditions. Now consider the Russian counterpart of (54) in (55a-b).

Russian (Sergey Avrutin, Arthur Stepanov, p.c.)

a.

Kto znaet gde chto kupila Marija?

who knows where what bought Maria

$\rightarrow \quad$ Only matrix WH answered: e.g., 'John knows where Marija bought what.'

b. Kto znaet chto kto kupil?

who knows what who bought

$\rightarrow \quad$ Only matrix WH answered: e.g., 'Bill knows who bought what.'

\footnotetext{
${ }^{13}$ A reviewer nicely points out that the conjecture that wH-in-situ in multiple question can involve non-cyclic movement interacts very closely with the Principle of Minimal Compliance (Richards, 2001): given that one wH has already moved to the matrix periphery, the PMC predicts that subsequent wHS should be free to move to the same target periphery without obeying island constraints. The question, then, would be how to refine the PMC in order to capture the islands effects when the second wave of movement does not target the matrix periphery, but rather a lower (embedded) periphery (i.e., the Romanian partial movement generalization in (51i)).

${ }^{14}$ Agüero-Bautista's (2001) generalization is that only wH-dependencies involving individual quantification can span an island (and, as such, involve non-cyclic, single swoop movement). wH-dependencies involving functional quantification are established via successive cyclic movement. Should this proposal be correct, then we would have to conclude that there are two mechanisms for deriving list readings:

i. Functional dependencies: trace/copy is interpreted as a skolem function and created via cyclic movement.

ii. Higginbotham and May's (1981) classic absorption analysis for paired answers with multiple questions: trace/copy is interpreted as an individual variable and created by non-cyclic movement.

We leave this issue open here.
} 
Both (55a) and (55b) involve a wH-phrase partially fronted to the left edge of a wH-island, and the questions allow only an answer to the matrix wH. That is, the partially fronted wH-phrase cannot be paired with the matrix wH, it can only get interpreted downstairs, inside the embedded question. In other words, the partially moved wH cannot be moved out of the wH-island at LF. We take this to show, once again, that a wH that has undergone overt cyclic movement (to the edge of CP2) cannot undergo further covert cyclic movement (to the edge of CP1) - if this movement violates island constraints, as is the case in (55). ${ }^{15}$

The evidence presented here for island effects at LF and, consequently, for covert successive cyclic movement, is important in light of recent proposals according to which successive cyclicity is uniformly reducible to PF Interface conditions on linearization, as proposed in particular by Fox and Pesetsky (2005). Under Fox and Pesetsky's proposal, covert movement applies after linearization and, as such, need not be successive cyclic and can violate island conditions. We conclude, here, that successive cyclicity and locality conditions on movement are not reducible to PF interface conditions. ${ }^{16}$

\section{A scope paradox}

On the basis of the overt syntax of multiple wh-movement in Romanian, we argued that trapped pair-list and the triple-list readings have a distinct syntax at $L F$. Triple-list readings arise when all three wH-phrases are scoped out to the matrix spec $\mathrm{CP}$ at LF, as shown in (56).

(56) Triple-list readings arise in multiple $L D$-movement configurations at $\mathrm{LF}$

a. LD-movement to the matrix $\mathrm{CP}$

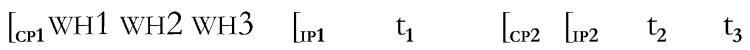

b. Covert movement of medial $\mathrm{WH}(\mathrm{s})$ to the matrix $\mathrm{CP}$ : no island
i. ${ }_{\mathrm{CP} 1} \mathrm{WH} 1$
IIP1 $t_{1}$
$\left[\begin{array}{lllll}\mathrm{CP} 2 & {[\mathrm{IP2}} & \mathrm{WH} 2 \mathrm{WH} 3 & \mathrm{t}_{2} & \mathrm{t}_{3}\end{array}\right.$
(Overt syntax)

ii. $\left[_{\mathrm{CP} 1} \mathrm{WH} 1 \mathrm{WH} 2 \mathrm{WH} 3 \quad[\mathrm{IP1}\right.$

$\mathrm{t}_{1} \quad\left[\begin{array}{llll}\mathrm{CP} 2 & { }_{\mathrm{IP} 2} & \mathrm{t}_{2} & \mathrm{t}_{3}\end{array}\right.$

In English, covert movement of the embedded in-situ wh-phrases is non-cyclic and, consequently, LD-list readings are available across islands $((9) /(10))$. In Romanian, LD list readings also require the embedded wH(s) to end up in the matrix CP at LF ((56a/bii)). However, movement (be it LD (56a) or partial-movement (56bi)) is overt and, as such, cyclic and sensitive to island conditions. Overt multiple LD-movement will thus be unavailable across islands (36) and multiple partial-movement to the periphery of an island (38)-(41b) will not yield an LD list reading since further covert movement from the periphery of the island is illicit.

Turning to trapped pair-list readings, we have argued that they arise when the wH-phrases undergo partial wH-movement to the edge of the embedded clause-be it in Romanian where partial-movement is overt or in

\footnotetext{
${ }^{15}$ In Romanian, when the matrix verb selects a question (as is the case in (55)), the trapped list reading is also unavailable. Thus, only the matrix wH can be answered in the Romanian equivalent of (55a) (Ratiu, p.c.):

(i) Cine stie unde ce a cumparat Maria?

who knows where what bought Mary?

Only matrix WH answered: e.g., 'John knows where Maria bought what.'

Note that the same constraint holds for (single wh-questions involving) single partial movement: the embedded clause (hosting the partially fronted wH-phrase) cannot be a selected question in either Hungarian or German. This property of scope-marking constructions is, however, subject to variation across languages since in at least Hindi scope-marking questions, the matrix verb can be a predicate selecting a wH-complement. See Horvath (2000) and Lipták and Zimmermann (2007) for discussion. (Single partial movement is discussed in section 6.1).

${ }^{16}$ A reviewer asks how we distinguish single step movement in (i) (which circumvents the island violation) from the two step movement in (ii) — on a derivation where $\mathrm{wH}_{2}$ and $\mathrm{wH}_{3}$ in (iia) would undergo further non-cyclic movement from the periphery of IP2 to the matrix CP.

(i) Single step movement: [CP1 WH1 WH2 WH3 [IP1 $\mathrm{t}_{1}\left[\begin{array}{lllll}\text { IIsLAND } & {[\text { Ir2 }} & \mathrm{t}_{2} & \mathrm{t}_{3}\end{array}\right.$

$\begin{array}{llllllllll}\text { (ii) a. Overt syntax: [CP1 WH1 } & {[\text { IIP1 }} & \mathrm{t}_{1} & {[\mathrm{ISLAND}} & {[\mathrm{IP2}} & \mathrm{WH} 2 & \mathrm{WH} 3 & {[\mathrm{IP2}} & \mathrm{t}_{2} & \mathrm{t}_{3}\end{array}$

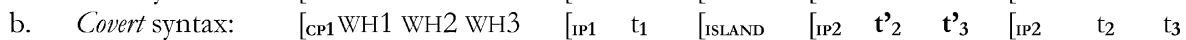

The point is well taken, but note however, the question arises on a derivational approach. On a representational approach, we can distinguish the chains in (i) and (iib), since only the latter contains intermediate traces in A'-positions (or copies under a copy theory of movement). Our goal here was merely to build an argument for locality effects on LF movement—-that is, against current assumptions that locality conditions are uniformly reducible to PF Interface conditions such as linearization.
} 
English where partial-movement is covert (and regardless of whether there is an island or not), as indicated in (57).

Trapped pair-list readings arise in multiple partial-movement configurations at LF.

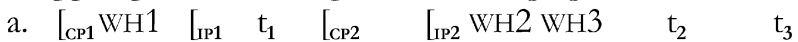

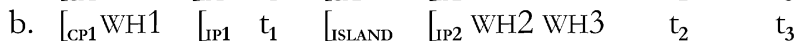

On the standard assumption that possible answers specify values for all and only those wH-expressions that have matrix scope, then trapped pair-list readings yield the scope paradox in (58).

\section{The Scope Paradox: \\ Under the trapped pair-list reading,}

a. $\quad$ All three whs are answered. Thus, all three whs have wide, matrix scope.

b. The (only) two wh-phrases that can be paired in the answer are, however, trapped in the syntax at the left-periphery of the subordinate clause.

The trapped pair-list reading (and likewise the list of trapped pair-list reading) raises two puzzles. First, it raisesfor multiple partial wH-movement-the canonical scope paradox that single partial wh-movement raises. That is, how do we assign matrix scope to $\mathrm{wH}(\mathrm{s})$ syntactically trapped at the periphery of an embedded clause. There are two solutions to this scope paradox in the literature for single partial wH-movement (see Dayal, 1996b, 2000; Horvath, 1997, 2000; and the contributions in Lutz and Müller, 1996; Lutz et al., 2000). On a Direct Dependency approach, the medial wH would undergo covert movement to the matrix Spec CP. But we have already ruled out the option of scoping out the medial wHS in (57) at LF-on the grounds that it incorrectly predicts that trapped pair-list and list of triples readings should be available in Romanian in the same syntactic configurations (section 5.1). In particular, recall that trapped pair-list readings are not available in configurations where all three whs have been overtly scoped out to the matrix CP and, conversely, that list of triples readings are unavailable with partially fronted wHs in island configurations. The second related question is how to account for the pairing asymmetries that LD lists with three wHphrases yield - that is, why can only the subordinate whs be paired independently of the matrix one. We suggest below a solution to the scope paradox in (58) by extending the Indirect Dependency approach advocated by Sternefeld (2001, 2002) and Lipták and Zimmermann (2007) for single partial movement (in languages like Hungarian, where a wH can be partially fronted to the periphery of an island) to multiple partial wH-movement.

\subsection{Towards a solution}

Consider the Hungarian LD question in (59) (discussed in Lipták and Zimmermann (2007:108) and Sternefeld (2002:17)), with a scope-marker in the matrix (miért) and partial-movement of a wh-phrase (kivel) to the periphery of a subordinate clause, itself embedded within an island. As is always the case with scope-marking questions, the answer specifies the embedded wH-item though, as Lipták and Zimmerman point out, the answer cannot specify the embedded wH-item alone, but rather the whole embedded wH-clause (e.g., (59c)). Long answers, together with the fact that covert LD-movement of the medial wH across the island in (59) would violate standard locality constraints, are two of the arguments given in the literature for LF clausal pied piping (see Horvath, 1997, 2000; Nishigauchi, 1990). On this analysis, there would be no violation of island constraints in (59) because it is not the medial wH that raises to spec CP at LF, but rather the entire embedded $\mathrm{CP}^{17}$
a. Miért vagy dühös [ ${ }_{\mathrm{Cp}}$ mert kivel ${ }_{1}$ találkoztál $\mathrm{t}_{1}$ what-FOR be-2SG angry because who-with met-2sG
b. Lit. 'Why are you angry, because whom you met?'
'Whom are you angry because you met?'
c. 'Because I met Peter.'

\footnotetext{
${ }^{17}$ von Stechow (1996) argues against Nishigauchi's (1990) theory of LF pied piping on the grounds that it yields uninterpretable LFs. Sternefeld (2001) develops a theory of pied piping which he argues is immune to the criticisms raised by von Stechow.
} 
Sternefeld (2001) and Lipták and Zimmermann (2007, henceforth L\&Z) extend Dayal's Indirect Dependency (IDA) approach to partial-movement in embedded argument clauses to cover partial-movement in embedded adjunct clauses, such as the because-clause in (59). On an IDA, the matrix scope marker is not directly linked to medial wH, but to the entire embedded clause, itself interpreted as a question on its own. The problem with generalizing this account to (59) is that the adverbial subordinate clause in (59) cannot be interpreted as an ordinary question. To solve this problem, Sternefeld and L\&Z propose a generalized question formation procedure. Assuming that question formation proceeds by forming sets of propositions out of a single open proposition, the basic idea is to generalize the procedure to different kinds of clauses containing a wH-element. For example, assuming that an adjunct because-clause denotes a set of propositions (that is, the denotation of a because $q$ clause is the set of all proposition $p$ such that $p$ holds by virtue of $q$ 's being true (see L\&Z: 126)), the idea is to generalize the question formation procedure so that the becauseclause in (59) denotes the set of sets of propositions described in (60). The type shifting operation that maps semantic objects of a given type $\langle\tau\rangle$ to a higher type $\langle\tau, \mathrm{t}\rangle$ (in the case at hand, sets of propositions (type $<$ st, $\mathrm{t}>$ ) onto sets of sets propositions (type $<<$ st,t, $>, \mathrm{t}\rangle$ )) is triggered by the presence of the wH-item in the adjunct clause.

(60) \{the set of propositions $\mathrm{p}$ such that $\mathrm{p}$ holds because you met a, the set of propositions $\mathrm{p}$ such that $\mathrm{p}$ holds because you met $b$, the set of propositions $\mathrm{p}$ such that $\mathrm{p}$ holds because you met $\mathrm{c}, .$.

Sternefeld then extends Reinhart's (1998) choice function analysis of wH-terms. The matrix wH in (59) is interpreted as a higher order choice function that selects one of the elements of the set of sets of propositions in (60)/(61a). Accordingly, the question in (59a) denotes (61b). This yields exactly the result we want since it gives us the set of possible answers in (61c).

(61) a. $\wp:=\{\wp: \exists x$ person $(\mathrm{x}) \& \wp=\lambda$ p. p because you met $\mathrm{x}\}$

b. $\{\mathrm{p}: \exists \mathrm{f}$ (choice function $(\mathrm{f}) \wedge \mathrm{p}=$ you are angry $\mathrm{f}(\wp)$ )

[see Sternefeld 2002:19]

c. \{You are angry because you met a, You are angry because you met b, You are angry because you met c, ... $\}$

With this background in mind, consider the multiple wh-question in (16a), repeated here as (62a). Recall that (62a) allows the trapped pair-list answer in (62b), where all three wHs are answered but only the two wHs trapped within the island are paired in the answer. By hypothesis, the trapped pair-list reading arises in the LF-configuration in (62c), where the subordinate wH-phrases have undergone partial-movement of the periphery of the subordinate clause, itself embedded within the adjunct island.

(62) a. Which teacher got upset because which boy had a fight with which girl?

b. The history teacher got upset because John had a fight with Mary, and Bill a fight with Susan.

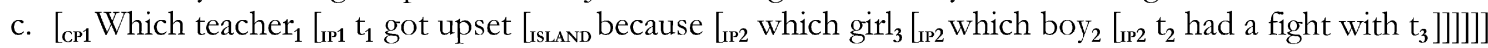

Our proposal is to adapt Sternefeld and L\&Z' Indirect Dependency Approach to (overt) single partial-movement in embedded adjunct clauses (the because-clause in (59) with a single partially fronted wH), to covert (in English)/overt (in Romanian) multiple partial-movement in embedded adjunct clauses (the because-clause in (62c) with two partially fronted wHs). In a nutshell, the idea is that the pair-list reading is confined to the two wHs trapped at the edge of the adjunct clause because the adjunct clause is interpreted as a multiple question on its own. That is, taking $\{a, c\}$ as the set of boys and $\{b, d\}$ as the set of girls, we want the because clause in (62c), with two whs to denote the set of sets of propositions in (63):

(63) \{the set of propositions $\mathrm{p}$ such that $\mathrm{p}$ holds because a had a fight with $\mathrm{b}$, and $\mathrm{c}$ had a fight with $\mathrm{d}$, the set of propositions $\mathrm{p}$ such that $\mathrm{p}$ holds because a had a fight with $\mathrm{d}$ and $\mathrm{c}$ had a fight with $\mathrm{b}$ \}

To get the because-clause in (62c) to denote the set of sets of propositions described in (63), we first apply a skolem function analysis (4) to the fronted object wH-expression which girl in (62c). That is, we assume that raising of which 
girl to the periphery of $\mathrm{IP}_{2}$ leaves a complex trace (the doubly indexed trace in (64)) consisting of a skolem function variable and an argument variable. (64) thus gives rise to a functional dependency between the subject term setting the domain of the function (boys) and the object term setting its range (girls).

$$
\text { [IP2 which girl } \left.{ }_{3}\left[{ }_{\mathrm{IP} 2} \text { which } \text { boy }_{2}\left[{ }_{\mathrm{IP} 2} \mathrm{t}_{2} \text { had a fight with } \mathrm{t}_{3}^{2}\right]\right]\right]
$$

The meaning of the because-clause in (65) can then be derived by Sternefeld and L\&Z's generalized question formation procedure, which yields the set of sets of proposition in (66), as the denotation of the because-clause in (65).

$$
\begin{aligned}
& \text { [CP because }\left[_{\text {IP2 }} \text { which } \operatorname{girl}_{3}\left[{ }_{\mathrm{IP} 2} \text { which boy }{ }_{2}\left[{ }_{\mathrm{IP} 2} \mathrm{t}_{2} \text { had a fight with } \mathrm{t}_{3}^{2}\right] 1\right]\right]
\end{aligned}
$$

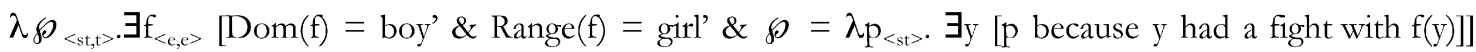

We then want to apply a higher order choice function to the set in (66). This choice function will select one of the elements in the set of sets of propositions in (66). To achieve this result, we assume that the because-clause in (65) contains an empty correlate with wH-features, base-generated at the edge of the clause, as shown in (67a). In Sternefeld (2001), $\varnothing_{+ \text {wн }}$ has a dual function. It serves as a trigger for LF pied piping of a constituent to the matrix spec CP and, moreover, is interpreted as the existentially closed (high order) choice function $(F)$ that selects one of the elements in the set denoted by the pied-piped constituent. Hence, (67a) is actually (67b). Clausal pied piping yields the structure in (68a).

(67) a. $\int_{\mathrm{CP}} \varnothing_{+\mathrm{WII}}\left[_{\mathrm{CP}}\right.$ because $\left[_{\mathrm{IP} 2}\right.$ which girl ${ }_{3}\left[_{\text {IP2 }}\right.$ which boy ${ }_{2}\left[_{\mathrm{IP} 2} \mathrm{t}_{2}\right.$ had a fight with $\left.\left.\mathrm{t}^{2}{ }_{3}\right]||\right]$

b. $\quad{ }_{\mathrm{CP}} \mathrm{F}\left[{ }_{\mathrm{CP}}\right.$ because ${ }_{\mathrm{IP} 2}$ which girl ${ }_{3}\left[_{\mathrm{IP} 2}\right.$ which boy ${ }_{2}\left[_{\mathrm{IP} 2} \mathrm{t}_{2}\right.$ had a fight with $\left.\left.\left.\left.\left.\mathrm{t}_{3}^{2}\right]\right]\right]\right]\right]$

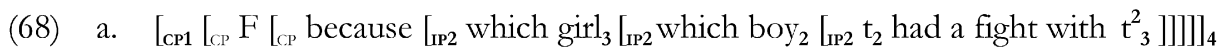
$\left[{ }_{\mathrm{CP} 1}\right.$ which teacher ${ }_{1}\left[\mathrm{IP}_{1} \mathrm{t}_{1}\right.$ got upset $\left.\left.\left.\mathrm{t}_{4}\right]\right]\right]$

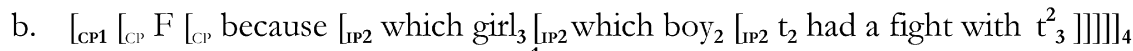
[CP1 which teacher ${ }_{1}\left[{ }_{\text {IP1 } 1} t_{1}\right.$ got upset $\left.\left.t_{4}^{1}\right]\right]$ ]

Finally, how do we relate the matrix wH-phrase to the (higher-order) choice function $\mathrm{F}$ that selects an element from the set denoted by its complement? We can achieve this via a skolem function mapping individuals to choice functions. That is, we assume that clausal pied piping leaves a functional trace that gets bound by the function's argument (the ccommanding subject term), as in (68b). The domain of the function is the set of teachers and the range of the function is the set of choice functions selecting an element in the set given in (66). On this proposal, (62a) would denote (69). The value of $f(x)$ in (69) is a choice function that applies to $\wp$ and yields one of the sets of propositions contained in $\wp$. The result is then applied to the matrix clause

$$
\begin{aligned}
& \lambda \mathrm{p} \exists \mathrm{f}_{<\mathrm{e},<\text { stt,stt>> }}[\operatorname{Dom}(\mathrm{f})=\mathrm{a} \text { CF of type }<\text { sttt, } \mathrm{stt}>\& \operatorname{Range}(\mathrm{f})=\text { teacher } \& \\
& \left.\mathrm{p}=\cap \lambda \mathrm{p}^{\prime} . \exists \mathrm{x}[\mathrm{p},=[\mathrm{f}(\mathrm{x})](\wp)(\mathrm{x} \text { got upset })]\right]
\end{aligned}
$$

Now, recall from our discussion of (18)-(19) in section 3 (repeated below as (71a-b)), that (70a) also allows a list of trapped pair-list readings: the answers in $(70 \mathrm{~b})$, just like those in $\left(71 \mathrm{a}^{\prime} / \mathrm{b}^{\prime}\right)$, list different values for the matrix as well as the embedded wHs, while at the same time pairing the embedded whs, independently of the matrix wH. Moreover, as argued in section 3, lists of trapped pair-list readings show the same pairing asymmetries as trapped pair-list readings: only the subordinate wHS can be paired independently of the matrix wH.

(70) a. Which teacher got upset because which boy had a fight with which girl?

b. The history teacher got upset because John had a fight with Mary and Bill a fight with Susan, and the math teacher got upset because Terry had a fight with Ann and Chris a fight with Clare.

(71) a. Which guest promised that which child would get which toy?

a'. John promised that Sybren would get a plane and Amina a train, and Terry promised that Zara would get a ball and Ilea a teddy bear. 
b. Which parent thanked Mary for giving which child which toy?

b'. John parent thanked Mary for giving Sybren a plane and Amina a train, and Terry thanked Mary for giving Zara a ball and Ilea a teddy bear.

Since the function $f$ in (69) pairs teachers with the 'choice' selected by the choice function (a set of propositions in the set of sets of propositions in (66)), we not only account for the core property of the trapped pair-list reading-that is, for why in sentences with three wH-phrases, two of which are embedded in a subordinate clause, only the two subordinate wH-phrases can be paired independently of the third/matrix wH—but we also predict the availability of lists of trapped pair-list readings. ${ }^{18}$

\section{Conclusion}

We close this paper by recapitulating the major theoretical implications that our analysis of (lists) of trapped pairlist readings (versus LD triple list readings).

We have argued that the availability of trapped pair-list readings in English provides evidence for covert partial movement in English, thus suggesting that partial movement may be universal.

We have argued that the unavailability of tripple-list readings in Romanian configurations involving multiple partial movement provides evidence for island effects at LF and, consequently for covert successive cyclic movement, thus suggesting that successive cyclicity may not be uniformly reducible to PF Interface conditions on linearization.

We have argued that trapped pair-list readings raise two correlated puzzles. That is, first, the canonical scope paradox that single partial wH-movement raises: how do we assign matrix scope to wH(s) syntactically trapped at the periphery of an embedded clause? Second, how do we account for the pairing asymmetries that LD lists with three wHphrases yield: why can only the subordinate wHs be paired independently of the matrix one? We have suggest that these puzzles can be resolved by extending Sternefeld (2001, 2002) and Lipták and Zimmermann's (2007) Indirect Dependency Approach to (overt) single partial-movement in embedded argument/adjunct clauses to covert (in English)/overt (in Romanian) multiple partial-movement in embedded argument/adjunct clauses. The basic insight driving this proposal is that only the subordinate wHs can be paired independently of the matrix wH because the subordinate clause can be interpreted as a multiple question on its own.

\section{References}

Agüero-Bautista, C., 2001. Cyclicity and the scope of wh-phrases, M.I.T.: PhD Dissertation.

Bittner, M., 1998. Cross-linguistic semantics for questions. Linguistics and Philosophy 21, 1-82.

\footnotetext{
${ }^{18}$ A reviewer asks why, on this proposal for the semantics of the trapped pair-list reading, multiple long-distance questions in Romanian do not admit a trapped pair-list reading via reconstruction of wH-phrases into the embedded clause. Obviously, if we allow the overtly fronted wH2 and wH3 in (49) (repeated as (i)) to be interpreted at LF in the periphery of the complement clause, then we lose our account for why questions involving multiple long-distance movement and questions involving multiple partial movement do not allow the same range of readings (since only the latter admit the trapped-pair list reading).

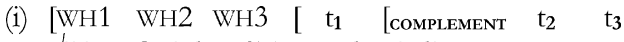

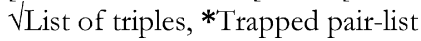

The same issue arises, however, for single partial movement. Single partial movement is not semantically equivalent to single long-distance movement and the indirect dependency approach was designed to capture these semantic differences (see Dayal, 1996a,b, 2000; Lipták and Zimmermann, 2007, and references therein for discussion). Now, if we were to allow a wh phrase that has undergone overt LD movement to be interpreted at LF in the periphery of the embedded clause via reconstruction, then LD and partial movement questions should be semantically equivalent, which they are not. The basic insight driving the indirect dependency approach is that a question involving partial movement can be interpreted as a question on its own and this is why it is not semantically equivalent to a LD question. We have argued here that the same insight can capture the pairing asymmetries in questions involving multiple partial movement: only the partially fronted wHs can be paired independently of the matrix wH because the subordinate clause can be interpreted as a multiple question on its own. If we were to allow reconstruction to the periphery of the complement clause (or alternatively to assume that interpretation proceeds phase by phase with the complement clause shipped off to interpretation on its own, as the reviewer also suggests), then we lose the basic insight driving the indirect dependency approach altogether.
} 
Bošković, Ž., 2001. On the Interpretation of Multiple Questions. Linguistic Variation Yearbook. John Benjamin's, Amsterdam.

Cheng, L.L.-S., Demirdache, H., in preparation. Cyclicity and covert movement. ms. Leiden University and Université de Nantes.

Chierchia, G., 1993. Questions with quantifiers. Natural Language Semantics 1.2, 191-234.

Comorovski, I., 1996. Interrogative Phrases and the Syntax-Semantics Interface. Kluwer Academic Publishers, Dordrecht, The Netherlands.

Dayal, V., 1996a. Locality in wh Quantification. Kluwer, Dordrecht.

Dayal, V., 1996b. Scope marking. Defense of Indirect Dependency. In: Lutz, U., Müller, G. (Eds.) Papers on 'Wh-Scope Marking'. (Arbeitspapiere des SFB 340, Bericht Nr. 76). Universität Tübingen. 107-130.

Dayal, V., 2000. Scope Marking: Cross Linguistic Variation in Indirect Dependency. In: Lutz, U., Müller, G., von Stechow, A. (Eds.), Wh-Scope Marking. Benjamins, Amsterdam, pp. 157-194.

Dayal, V., 2002. Single-pair versus multiple-pair answers: wh-in situ and scope. Linguistic Inquiry 33, 512-520.

Engdahl, E., 1986. Constituent Questions. Reidel, Dordrecht.

É. Kiss, K., 1993. Wh-movement and specificity. Natural Language and Linguistic Theory 11, 85-120.

Fox, D., Pesetsky, D., 2005. Cyclic linearization of syntactic structure. Theoretical Linguistics 31, 1-45.

Grebenyova, L., 2004a. Interpretation of slavic multiple Wh-questions. In: Arnaudova, O., Browne, W., Rivero, M.L., Stojanović, D., (Eds.), Proceedings of the Annual Workshop on Formal Approaches to Slavic Linguistics (FASL 12). Ann Arbor: Michigan Slavic Publications, pp. $169-186$.

Hagstrom, P., 1998. Decomposing Questions. Doctoral Dissertation, Massachusetts Institute of Technology, Cambridge.

Higginbotham, J., May, R., 1981. Questions, quantifiers and crossing. The Linguistic Review 1, 41-79.

Hornstein, N., 1995. Logical Form: From GB to minimalism. Blackwell, Cambridge, Mass.

Horvath, J., 1997. The status of 'WH-expletives' and the partial WH-movement construction of Hungarian. Natural Language and Linguistic Theory $15,509-572$.

Horvath, Julia, 2000. On the Syntax of 'Wh-Scope Marker' constructions: some comparative evidence. In: Lutz, U., Müller, G., von Stechow, A. (Eds.), Wh-Scope Marking. Benjamins, Amsterdam, pp. 271-316.

Ito, S., 2005. Single-pair answers and pair-list answers in wh-questions with singular wH. MA thesis. University of Tokyo.

Lewis, John D., 1999. On multiple wh-questions: weak crossover, D-linking, and the third wh-phrase effect. In: Bird, S., Carnie, A., Haugen, Jason D., Norquest, P. (Eds.), WCCFL 18: Proceedings of the 18th West Coast Conference on Formal Linguistics.

Lipták, A., Zimmermann, M., 2007. Indirect scope marking again: a case for generalized question formation. Natural Language and Linguistic Theory 25, 103-155.

Lutz, U., Müller, G. (Eds.), 1996. Papers on 'Wh-Scope Marking'. (Arbeitspapiere des SFB 340, Bericht Nr. 76). Universität Tübingen.

Lutz, U., Müller, G., von Stechow, A. (Eds.), 2000. Wh-Scope Marking. Benjamins, Amsterdam.

Nishigauchi, T., 1990. Quantification in the Theory of Grammar. Kluwer Academic Publishers, Dordrecht.

Ratiu, D., 2005. Questions multiples en Roumain. Master 2 thesis, Université de Nantes.

Ratiu, D., 2007. Evidence for (counter) cyclic movement from Romanian. Paper presented at the 37th Linguistics Symposium on Romance Languages.

Richards, N., 2001. Movement in Language: Interactions and Architectures. Oxford University Press, Oxford.

Reinhart, T., 1998. Wh-in situ in the framework of the minimalist program. Natural Language Semantics 6, $29-56$.

von Stechow, A., 1996. Against LF pied-piping. Natural Language Semantics 4, 57-110.

Sternefeld, W., 2001. Partial movement constructions, pied piping, and higher order choice functions. In: Féry, C., Sternefeld, W., (Eds.), Audiatur Vox Sapientiae. A Festschrift for Arnim von Stechow (pp. 473-486). Berlin: Akademieverlag.

Sternefeld, W., 2002. Wh-expletives and partial Wh-movement: two non-existing concepts? In: Abraham, W., Zwart, C.J.-W. (Eds.), Issues in Formal German(ic) Typology. John Benjamins, Amsterdam, pp. 285-305. 